\title{
Removal of foreign bodies from the foot, a technique using high elevation and local anaesthesia
}

\author{
S. N. MARDEL \\ Accident $\mathcal{E}$ Emergency Department, Leicester Royal Infirmary, Leicester, England
}

\section{SUMMARY}

The use of a steep Trendelenburg position is described in removing foreign bodies from the foot. Bleeding at the site is sufficiently reduced to allow removal without a tourniquet. Retrospective analysis of theatre records demonstrates a considerable reduction in the number of general anaesthetics given since the introduction of this technique.

\section{INTRODUCTION}

The removal of a small foreign body deeply embedded in the sole of the foot is a common problem facing staff in A\&E departments. To find these foreign bodies (often a piece of glass or needle), a pneumatic tourniquet has usually been used to produce a bloodless field. A thigh-tourniquet causes even more severe pain than an armtourniquet and cannot be tolerated without either a general anaesthetic or a complex regional nerve block. Thus, for a small procedure the patient often faces the inconvenience, morbidity and risk of a general anaesthetic (Lunn \& Mushin, 1982; Hardwick \& Alderton, 1987). Since the patient is seldom starved on presentation, delay is inevitable with all its disadvantages.

\section{METHOD}

The technique of per-operative elevation is familiar to neurosurgeons, E.N.T. and plastic surgeons for limiting bleeding at the operative site. It has limitations imposed in head and neck surgery by proximity to the heart. For the foot, however, elevation of

Correspondence: Dr S. Mardel, Registrar in Accident and Emergency, Accident and Emergency Department, Leicester Royal Infirmary, Infirmary Square, Leicester LE1 SWW, England 
$0.7 \mathrm{~m}$ above the level of the heart is easily achieved by placing the patient in a steep? Trendelenburg position (see Figure 1). It reduces bleeding at the site of incision tô almost nothing, without the use of a tourniquet. For local anaesthesia infiltration with plain lignocaine or bupivacaine is used, the latter being useful in reducing post operative pain. Painful injection through the sole of the foot is avoided by injecting either from the side or through the dorsum of the foot.

Contraindications include inability to cooperate with the technique (usually young children), or discomfort on adopting the position (such as patients with congestivecardiac failure).

\section{RESULTS}

In comparing the 6 month periods before and after the introduction of this technique into our department, we have reduced the frequency with which a general anaesthetie

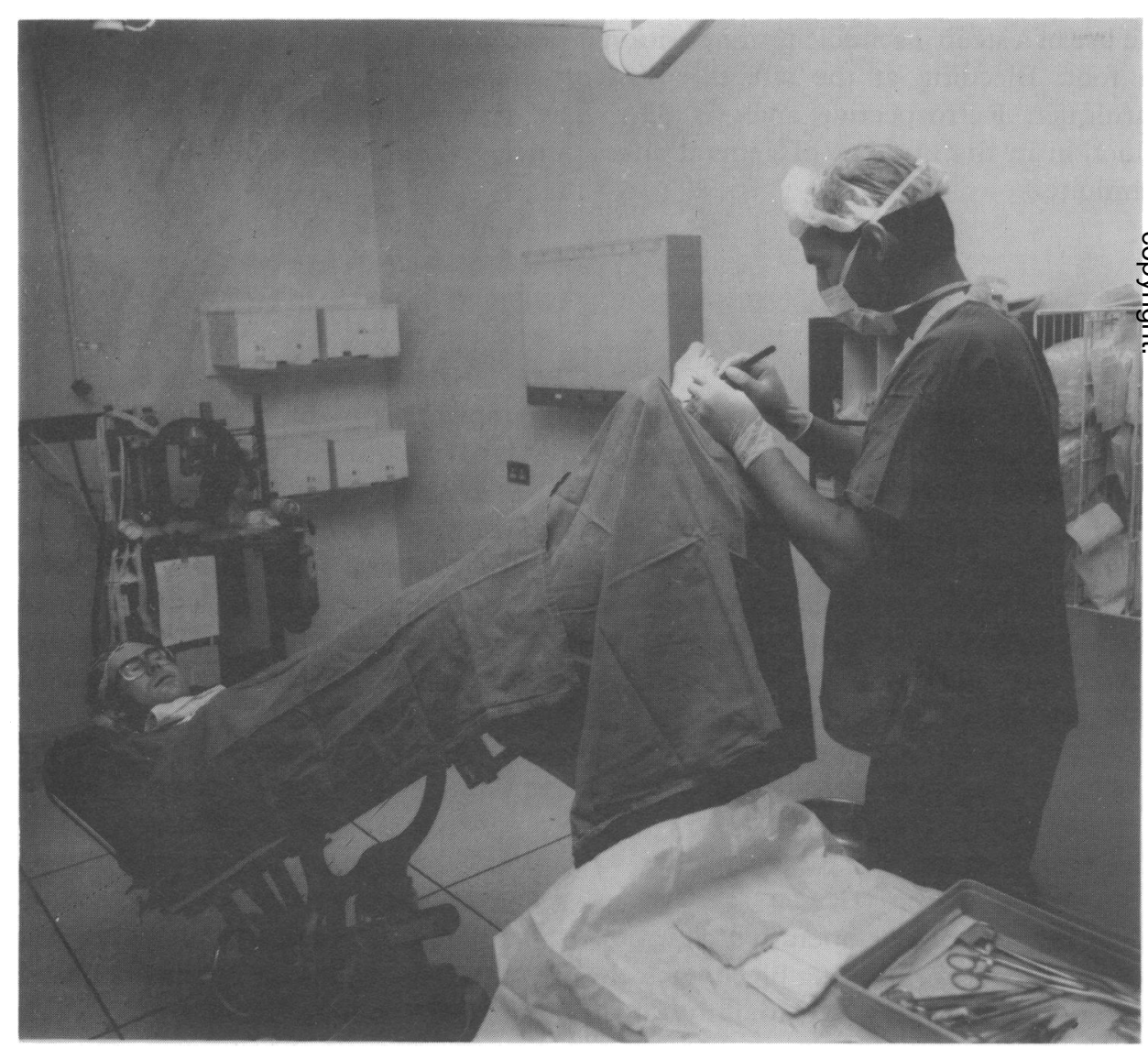

Fig. 1. The steep Trendelenburg position. The patient is more comfortable with the head of the table tilted (thus flexing the neck). 
was needed for this procedure from $73 \%$ (total number of patients $=37$ ) to $17 \%$ (total number of patients $=42$ ). The foreign body was found in all the cases where this technique was used, and all the patients were pleased that they had not required a general anaesthetic. The few cases where the technique had not been used were in children under the age of seven, or where the surgeon was not aware of the method.

As well as obvious savings in terms of cost and time, the patient avoids the problems associated with general anaesthesia and the use of a tourniquet (Editorial, Canadian Medical Association Journal, 1973).

\section{REFERENCES}

Hardwick, M. \& Alderton, J. D. (1987) Morbidity following out-patient anaesthesia in an accident and emergency department. Today's anaesthetist, 2, (1), 6-8.

Lunn, J. R. \& Mushin, W. W. (1982) Mortality associated with anaesthesia. Nuffield Provincial Hospital Trust, London.

(Editorial) The tourniquet: Instrument or weapon? (1973), Canadian Medical Association fournal, 109: 827-9. 